\title{
IMAGEM E POSICIONAMENTO - O CASO DAS FACULDADES INTEGRADAS DO PARANÁ (FIP) ${ }^{1}$
}

\author{
Clara Isabel Koetz \\ Universidade de Santa Cruz do Sul (UNISC) \\ clara_koetz@uol.com.br \\ Douglas Wegner \\ Universidade de Santa Cruz do Sul (UNISC) \\ dwegner@unisc.br
}

Carin Maribel Koetz

Faculdades Integradas de Taquara (FACCAT) / Faculdade Novo Hamburgo (IENH)

carink06@gmail.com

Submissão: 18/05/2012

Aprovação 23/01/2013

\begin{abstract}
Resumo
O caso apresenta a situação das Faculdades Integradas do Paraná - FIP, uma instituição de ensino superior que enfrenta problemas de imagem e de comunicação com os seus públicos. Estes problemas foram advindos de um crescimento intenso que a instituição teve ao longo da sua história e que se intensificou a partir do ano de 2005. Um grupo de professores, ciente dessas dificuldades, realizou uma pesquisa com diversos públicos internos, como professores, coordenadores, reitor e pró-reitores, técnicos administrativos e acadêmicos e externos, como vestibulandos, agência de comunicação e imprensa, com o objetivo de identificar a imagem ideal e a imagem percebida em relação a FIP. Os resultados, que foram complementados com informações de pesquisas realizadas anteriormente, apontam diferenças entre a imagem considerada ideal e a imagem real nos mais diversos públicos. A partir dessas informações, os alunos são estimulados a analisar os problemas identificados e a propor uma estratégia de comunicação integrada, que permita reverter as falhas na comunicação e modificar a percepção da imagem da instituição.
\end{abstract}

Palavras-Chave: Comunicação Integrada de Marketing; Posicionamento; Imagem da Marca; Brand Equity.

\footnotetext{
${ }^{1}$ Este caso de ensino foi elaborado com base em uma situação vivenciada por uma organização real. Entretanto, o nome da organização, bem como os personagens, diálogos e eventos descritos, são fictícios.
} 


\begin{abstract}
The case presents the situation of Faculdades Integradas do Paraná - FIP, a high level education institution that faces image and communication problems with its publics. These problems arose from an intensive growth that the Institution has had throughout its history, which was intensified after 2005. A group of professors, aware of these difficulties, conducted a research with several internal publics, such as professors, department managers, dean, students, as well as external publics, such as student candidates and communication and press agencies, in order to identify the ideal and the perceived image in relation to the FIP. The results, which were supplemented with information from previous research, show differences between the ideal and the real image in the most diverse publics. From the information obtained through the research, the students are motivated to analyze the problems identified and propose an integrated communication strategy, which enables to solve the communication failures and modify the Institution image perception.
\end{abstract}

Key words: Integrated Marketing Communications, Positioning, Brand Image, Brand Equity. 


\section{Introdução}

Carla recosta-se em sua cadeira, suspirando. Finalmente, após vários meses de trabalho árduo, tem em suas mãos a versão final do diagnóstico de comunicação das Faculdades Integradas do Paraná (FIP). Com os olhos ligeiramente fechados, pensa em todos os desafios e dificuldades vivenciados por ela e por sua equipe que culminaram naquelas 77 páginas: 290 pessoas entrevistadas, observações em ambientes não formais, análise de pesquisas anteriores; enfim, um conjunto de informações de extrema relevância para a instituição, cujo resumo estava, neste momento, sobre sua mesa. Os resultados confirmaram diversas questões anteriormente identificadas pelo grupo, como falhas na comunicação interna e problemas de imagem que a FIP apresentava junto aos seus públicos externos. Embora uma parte do trabalho houvesse sido feita, ela sabia que a equipe ainda tinha um grande desafio pela frente - definir estratégias e táticas de comunicação com os diferentes públicos da instituição, a fim de solucionar os problemas identificados e permitir que a FIP fortalecesse a sua imagem e posicionamento no mercado. Neste momento, sentindo um misto de alívio pela sensação de missão cumprida e de expectativa em relação ao que ainda deveria ser feito, Carla relembra, em detalhes, todo o processo.

\section{A Situação}

Tudo havia começado no primeiro semestre de 2011. Carla atuava como professora de comunicação há pouco mais de quatro anos. Para ela e os demais colegas da área os problemas enfrentados pela FIP no tocante à comunicação interna eram escancarados: técnicos administrativos, gestores e docentes tinham ideias divergentes a respeito de questões como a política de ensino, qualidade e recursos humanos; em meio a uma enxurrada de emails diários, questões importantes acabavam se perdendo e decisões simples, como a definição de uma reunião, tornavam-se problemáticas. A situação se agravava pelo fato de não haver um departamento que concentrasse as ações de comunicação da instituição. Assim, informações vinham de todos os setores, de tamanhos, formatos e com conteúdos diferentes. As funções não eram bem definidas; muitas pessoas envolvidas, mas sem nenhuma diretriz básica que definisse os contornos que a comunicação interna deveria ter.

Em relação à comunicação externa, a situação não era diferente. A imagem da FIP, na opinião de Carla, ficava comprometida pela falta de um posicionamento claro; as diversas 
campanhas, que geralmente iam ao ar no período pré-vestibular, tinham a função de aumentar o número de alunos inscritos e adotavam propostas distintas, sem nenhum fio condutor que as unisse no sentido de estabelecer uma imagem para a FIP. Este problema era agravado pelo fato de serem feitas poucas campanhas institucionais, que contribuíssem para a construção de uma imagem única e consistente.

Naquela época, Carla costumava compartilhar as suas angústias com um grupo de professores, do qual fazia parte Antônio, professor de comunicação, que estava finalizando o seu doutorado e cujo tema de tese era justamente a imagem e o conceito; Daniela, coordenadora do curso de Administração, que fazia parte do quadro de professores da FIP havia 15 anos; Tomás, professor de pesquisa de marketing, e Sílvia, professora de marketing. O grupo encontrava-se geralmente às quintas-feiras pela manhã, na sala dos professores do Bloco B. Depois da aula, costumavam conversar sobre a FIP. No íntimo, o que unia a todos era o desejo de fazer alguma coisa, de colocar em prática, na própria instituição em que trabalhavam, um pouco do conhecimento adquirido ao longo de tantos anos de estudo e que era compartilhado com os alunos a cada aula.

Carla lembrava muito bem do dia em que Antônio havia proposto:

- E se fizéssemos uma pesquisa para identificar formalmente todos os problemas que conhecemos e depois apresentássemos para a Reitoria?

Todos se entreolharam, interessados na ideia.

- Pesquisa? Perguntou Sílvia. Acho que uma pesquisa seria extremamente importante, continuou ela, mas ela é apenas o primeiro passo. Deveríamos fazer um plano de comunicação, que identificasse os problemas e, posteriormente, propusesse estratégias e ações de melhoria.

Todos consentiram, fazendo movimentos afirmativos com a cabeça. Daniela emendou:

- Mesmo porque já foram feitas inúmeras pesquisas na FIP. Poderíamos fazer um trabalho que utilizasse estas pesquisas, adicionando novos dados, como entrevistas com professores, funcionários e alunos, a fim de buscarmos a opinião dos diversos públicos que se relacionam com a instituição.

- Poderíamos fazer um diagnóstico inicial, complementou Antônio, e a partir de então, delinearmos estratégias e ações que pudessem melhorar a comunicação e a imagem geral da FIP.

- Então está combinado, disse Tomás, levantando-se abruptamente, vamos fazer um plano de comunicação para a FIP! 
Ouvindo as palavras de Tomás, o grupo percebeu o quanto eles haviam devaneado. Não podiam simplesmente começar a fazer um trabalho como esse sem a autorização da Reitoria. Daniela sugeriu que o grupo encaminhasse uma solicitação ao Reitor antes de iniciar o trabalho.

Antônio concordou:

- Posso ficar responsável por fazer esta solicitação. Alguém disposto a me ajudar?

Todos levantaram as mãos ao mesmo tempo. O grupo entreolhou-se e todos riram. A vontade de fazer alguma coisa era visível.

\section{As Faculdades Integradas do Paraná (FIP)}

Localizada no Oeste do Paraná, a FIP foi criada pelo Grupo MBA no final dos anos 1990 a partir da aquisição de várias faculdades independentes, que atuavam na mesma região geográfica. O seu objetivo era ofertar cursos de ensino superior aos seus habitantes, contribuindo para o desenvolvimento socioeconômico da região.

Ao longo de sua existência, a FIP vem apresentando rápido crescimento. No período entre 2005 e 2010 o número de alunos triplicou, sendo que atualmente a instituição possui 18.539 alunos. De fato, grande parte deste crescimento foi reflexo das políticas de gestão adotadas pela instituição, além da própria expansão que o ensino superior vem apresentando no Brasil. Em 2010, a FIP contava com 39 cursos de graduação, 21 cursos de pós-graduação lato sensu, 1 Mestrado em Desenvolvimento Regional, 5 grupos de pesquisa, com 18 projetos em execução, 45 projetos de extensão e centro de idiomas.

Porém, é comum que organizações que passam por períodos de crescimento muito acelerado apresentem, em contrapartida, algumas sequelas. No caso da FIP, a estrutura organizacional teve dificuldade em acompanhar a evolução dos cursos, do número de alunos e de funcionários. Além disso, estes problemas foram agravados pelo fato da FIP ter se originado a partir da junção de diversas faculdades, com estruturas de gestão e culturas diferentes, bem como por não haver, até aquele momento, um departamento que fosse responsável pela centralização das ações de comunicação da instituição. Mas esta situação seria modificada em breve. 


\section{O Projeto}

Quando Sílvia entrou na sala, Antônio recém havia iniciado a reunião.

- Pessoal, eu imagino que todos vocês já sabem o motivo desta reunião. Tivemos a aprovação para fazer um diagnóstico da comunicação e imagem da FIP, bem como para propor melhorias a nível estratégico e tático.

- É um grande compromisso, mas estou muito feliz por termos iniciado este processo e, principalmente, por vocês terem compartilhado esta ideia juntamente comigo, prossegui Antônio.

- Bom, sendo assim, disse Sílvia, o negócio agora é arregaçarmos as mangas e começarmos a trabalhar.

De fato, trabalho não faltou para o grupo nos meses que sucederam aquela reunião. Antônio foi designado coordenador do projeto, pelo alinhamento que havia entre o seu tema de tese e o trabalho a ser desenvolvido. Assim, embora o trabalho fosse de natureza empírica, um grande embasamento teórico foi utilizado a fim de dar sustentação à pesquisa.

A pesquisa foi realizada de junho a dezembro de 2011 e tinha como principais objetivos:

- Compreender e explicar os processos de comunicação, de cultura e de relacionamento da FIP, bem como a construção de sua imagem, idealizada e percebida, pelos diferentes públicos;

- Avaliar os conceitos associados à FIP e identificar aqueles que deveriam ser articulados e instituídos para o seu reconhecimento;

- Propor estratégias de comunicação que contemplassem as necessidades de comunicação e informação da instituição;

- Definir práticas de comunicação coerentes com as estratégias, abordando os conceitos e as necessidades de comunicação identificadas.

Os dados foram coletados por meio de diferentes técnicas, como entrevistas, depoimentos, grupos focais, pesquisa documental, observações e sondagens. O grupo optou pela definição de "conceitos norteadores", os quais serviram de base para todas as entrevistas e grupos focais. Dessa maneira, os pesquisadores puderam adequar as questões de acordo com as necessidades de informações da investigação e, por outro lado, levar em consideração a história, o contexto e as características particulares do entrevistado e/ou do grupo de trabalho. Foram definidos os seguintes conceitos norteadores: imagem ideal, imagem percebida, comunicação, cultura, relacionamento e poder. Além das técnicas já citadas, foram realizadas 
observações em ambientes não oficializados (tais como refeitório, biblioteca, salas dos professores, corredores e filas nos setores de atendimento), a fim de coletar novas informações que foram, posteriormente, comparadas com as existentes.

No total, foram entrevistadas 290 pessoas, advindas dos seguintes públicos/ setores: Reitoria (5), agência de comunicação (1), imprensa (3), técnico-administrativos (35), coordenadores de curso (31), acadêmicos em início de curso (23), acadêmicos formandos (32), acadêmicos em estágios intermediários de curso (46), professores (47), representantes do Diretório Central de Estudantes - DCE (4) e vestibulandos (63). Também foram analisadas as respostas dadas pelos acadêmicos e potenciais estudantes em pesquisa de imagem realizada anteriormente. Da mesma forma, os estudos das pesquisas de clima já realizados forneceram importantes subsídios para comparação, compreensão e explicação das informações coletadas. Os resultados da pesquisa são descritos a seguir.

\section{Resultados}

O conceito mais citado pelos diversos públicos pesquisados foi a inovação. Pode-se dizer que a FIP é percebida como inovadora, pois os seus públicos a reconhecem como uma instituição em permanente processo de inovação. Tal conceito caracteriza-se por aspectos relacionados à tecnologia, propostas pedagógicas, projeto arquitetônico, formas de avaliação, formas de inclusão e projetos e ações de vanguarda. Em seguida, e de forma relacionada à inovação, aparece o conceito de crescimento. Assim, os públicos são unânimes em afirmar que a FIP tem apresentado crescimento acelerado (especialmente em termos de estrutura material e número de cursos e alunos). Assim como a inovação, a qualidade de ensino foi um valor pontuado pelos públicos como fundamental. Este tema pode ser percebido na extração de um depoimento: "não existe alternativa que não seja a da qualidade do ensino"; ou se tem qualidade ou se é desqualificada como instituição de ensino superior.

Outra constatação evidenciada nos resultados foi a percepção, entre os funcionários, administração superior e os alunos, de um clima de "espírito familiar", o qual permeia os diversos relacionamentos na instituição. Este clima, se por um lado traz aspectos positivos, como a proximidade afetiva entre os públicos e uma certa predisposição à tolerância, à diversidade e à cooperação, por outro lado pode tornar-se nocivo no sentido de permitir certos tipos de comportamento, comum às famílias, mas que são inadmissíveis no contexto profissional. Assim, as altas doses de afetividade e condescendência podem trazer como 
consequência alguns comportamentos não desejáveis, como a não observação das hierarquias, a falta de limites e a sobreposição de práticas paternalistas aos critérios de responsabilidade, avaliação de desempenho e competência.

Conceitos relacionados à seriedade e credibilidade também foram identificados nos dados coletados. De extrema importância, estes temas trazem à tona o papel de agente responsável, bem como a presença atuante desempenhada pela FIP na sociedade, na forma de ações e projetos de preservação do meio-ambiente e de promoção da cultura local. Estes conceitos foram identificados em diversos públicos, podendo ser exemplificados com a seguinte fala "se a FIP está envolvida pode ter certeza que vem coisa boa por aí" (fragmento de depoimento). No geral, eles significam que a instituição é uma referência de qualidade, de respeito e de compromisso.

Associado ao conceito anterior, a questão da transparência, que está relacionada ao acesso amplo e verdadeiro dos diversos públicos à informação, também foi identificada. A difusão das informações com seriedade e responsabilidade, de forma a evitar os boatos e especulações, tende a minimizar, e até mesmo a neutralizar, os problemas de imagem de uma organização. Os resultados demonstraram que a FIP possui práticas estabelecidas de divulgação de informações aos diversos públicos. Porém quando se tratam de casos críticos, essa premissa tende a ser desconsiderada. Embora tenha sido identificado, na maioria dos casos, o empenho da instituição no sentido de difundir informações, em situações difíceis, relacionadas a assuntos polêmicos, o fluxo de informações tende a ser reduzido. Isso amplia o espaço para a geração de boatos e especulações.

O desejo de ser um centro de referência foi expresso pelos diversos públicos. Simbolicamente, ser referência significa ser o modelo a ser seguido, copiado, referenciado, imitado. Trata-se de um longo processo de construção a partir de todas as pequenas ações. A FIP tem trilhado um longo caminho nessa direção, qualificando o seu corpo docente e de pesquisadores para tornar-se um centro de excelência nas mais diversas áreas. Nesse sentido, é mais apropriado afirmar que a instituição está capitalizando esse valor simbólico. Outro aspecto relevante é que a consolidação da FIP como centro de referência dependerá, também, da avaliação que a sociedade faz dos egressos que chegam ao mercado de trabalho. Observese que as competências e resultados conseguidos por esses profissionais no mercado de trabalho são associados à instituição na qual desenvolveram os seus estudos. $\mathrm{Na}$ mesma direção, os processos de avaliação do Ministério da Educação (MEC), ratificam os resultados.

Algumas citações trouxeram à tona aspectos negativos, por meio de afirmações que desqualificam a instituição. Assim, termos como “desorganizada”, “interiorana'”, 
"conservadora" e "fragmentada" foram utilizados por determinados públicos. Os técnicos administrativos, por exemplo, enfatizaram a questão da fragmentação, identificando-a tanto em discursos como em práticas. $\mathrm{O}$ conceito refere-se ao fato de não haver um discurso institucional que oriente a todos aqueles que estão em contato direto com os públicos externos a FIP, como alunos, imprensa e comunidade. Esta dissonância discursiva é facilmente percebida pelos públicos: a) nos eventos que ocorrem na comunidade e que a instituição se faz presente e/ou representar; b) nos próprios eventos institucionais; c) nos processos de negociação para realização de parcerias, venda de cursos e/ou projetos (cada pessoa, curso e instituto age conforme acredita que deva fazê-lo); d) nas campanhas publicitárias que mudam de foco conceitual a todo o momento.

A noção de conservadora mantém uma estreita relação com a cultura da região na qual a instituição está inserida. Nesse sentido, a dificuldade que os gestores da instituição têm de implementar mudanças foi uma característica identificada nos públicos técnicos administrativos e professores. O modelo de decisão é percebido como conservador no sentido de haver uma ênfase, na administração, de "se manter as coisas como estão". Os resultados demonstraram que, mesmo que em algumas situações os gestores demonstram que gostariam de efetuar algumas mudanças, na prática há uma tendência de manutenção do status quo, fazendo com que as coisas continuem como estão.

Por fim, o termo "interiorano", o qual foi identificado especialmente junto aos técnicos administrativos, possui forte ênfase negativa, pois está associado a aspectos considerados negativos pela sociedade urbana. Assim, por "interiorano" procura-se definir, dentre outras coisas, aquele que é ingênuo, não é estratégico, tem um ritmo mais lento, é muito conservador, pouco evoluído, tem uma administração autoritária ou do tipo familiar.

A Tabela 1 apresenta um resumo dos principais conceitos identificados na pesquisa no tocante à imagem percebida e ideal da FIP.

\section{Discussão do Diagnóstico - Quais os Caminhos para a FIP?}

Carla estava refletindo sobre o diagnóstico da pesquisa em relação à imagem da FIP quando seus colegas chegaram para a reunião. Ela começou a reunião assim que todos estavam acomodados em suas cadeiras.

- Bom, como todos sabem, o nosso diagnóstico ficou pronto. Porém, o nosso trabalho não termina aqui.

- Na verdade, ele está apenas começando, diz Sílvia. 
- É verdade, concorda Carla, o nosso compromisso com a Reitoria é de propor estratégias e táticas a fim de revertermos os problemas que identificamos. Assim, fiz uma lista das questões que considero mais relevantes e pelas quais acho que devemos começar a nossa análise:

- Quais os problemas de comunicação identificados na FIP?

- Quais os problemas identificados em relação à imagem da FIP?

- Qual o posicionamento que a FIP deve estabelecer?

- Que estratégias e ações de comunicação integradas, utilizando as diversas ferramentas (propaganda, relações públicas, publicidade, Internet, etc) podem ser sugeridas a fim de estabelecer e consolidar a imagem da FIP?

- Como a FIP deve gerenciar o seu brand equity ${ }^{i}$ ? 


\begin{tabular}{|c|c|c|c|c|c|c|}
\hline IMAGEM & $\begin{array}{l}\text { Reitor, Pró-Reitores e } \\
\text { Coordenadores }\end{array}$ & $\begin{array}{l}\text { Técnicos } \\
\text { Administrativos }\end{array}$ & Professores & Acadêmicos calouros & $\begin{array}{l}\text { Acadêmicos formandos, } \\
\text { Representante do DCE e } \\
\text { Vestibulandos }\end{array}$ & $\begin{array}{lr}\text { Agência } & \text { de } \\
\text { Comunicação } & \text { e } \\
\text { Imprensa } & \end{array}$ \\
\hline $\begin{array}{l}\text { Imagem } \\
\text { Percebida }\end{array}$ & $\begin{array}{l}\text { Inovação } \\
\text { Crescimento } \\
\text { Espírito familiar } \\
\text { Ensino em processo de } \\
\text { qualificação } \\
\text { Credibilidade } \\
\text { Envolvida com a } \\
\text { comunidade } \\
\text { Informal (estrutura e } \\
\text { processos) } \\
\text { Proximidade (geográfica) } \\
\text { Proximidade } \\
\text { (relacionamento) }\end{array}$ & $\begin{array}{l}\text { Comprometida com a } \\
\text { cidade } \\
\text { Família } \\
\text { Inovação } \\
\text { Está se qualificando } \\
\text { Crescimento } \\
\text { Desorganização } \\
\text { Interiorana } \\
\text { Conservadora }\end{array}$ & $\begin{array}{l}\text { Problemas } \\
\text { crescendo com a } \\
\text { instituição } \\
\text { Inovação } \\
\text { Seriedade } \\
\text { Fragmentada } \\
\text { Crescimento } \\
\text { Não é marca } \\
\text { reconhecida } \\
\text { Envolvida com a } \\
\text { comunidade }\end{array}$ & $\begin{array}{l}\text { Crescimento rápido e } \\
\text { constante } \\
\text { Inovação } \\
\text { Cursos diferenciados } \\
\text { Seriedade } \\
\text { Compromisso cl a } \\
\text { comunidade } \\
\text { Organizada } \\
\text { Nome e imagem legal } \\
\text { Cara } \\
\text { Fácil de entrar } \\
\text { Próxima } \\
\text { Não lembra de conceito } \\
\text { específico } \\
\text { Qualidade de ensino }\end{array}$ & $\begin{array}{l}\text { Crescimento } \\
\text { Inovação } \\
\text { Cursos diferenciados } \\
\text { Seriedade } \\
\text { Qualidade } \\
\text { Compromisso com a } \\
\text { comunidade } \\
\text { Professores mais teóricos e } \\
\text { menos práticos } \\
\text { Cara } \\
\text { Próxima } \\
\text { Fácil de entrar }\end{array}$ & $\begin{array}{l}\text { Inovação } \\
\text { Qualidade de ensino } \\
\text { Seriedade } \\
\begin{array}{l}\text { Compromisso com a } \\
\text { comunidade }\end{array}\end{array}$ \\
\hline $\begin{array}{l}\text { Imagem } \\
\text { Ideal }\end{array}$ & 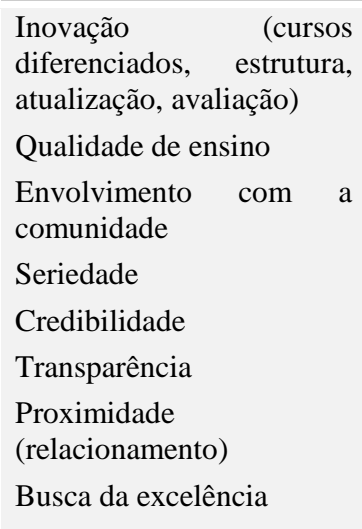 & $\begin{array}{l}\text { Excelência } \\
\text { Busca de reconhecimento } \\
\text { Sucesso } \\
\text { Comprometida com a } \\
\text { cidade } \\
\text { Inovação } \\
\text { Qualidade de ensino } \\
\text { Acessibilidade / familiar } \\
\text { Eficácia, eficiência, } \\
\text { reconhecimento externo } \\
\text { Concorrida (não deve } \\
\text { caçar alunos) }\end{array}$ & $\begin{array}{lr}\text { Qualidade } & \text { de } \\
\text { ensino } & \\
\text { Visibilidade } & \\
\text { Inovação } & \\
\text { Seriedade } & \\
\text { Centro } & \text { de } \\
\text { referência } & \text { em } \\
\text { pesquisa } & \\
\text { Transparência } & \end{array}$ & Referência de mercado & $\begin{array}{l}\text { Referência na qualidade de } \\
\text { ensino } \\
\text { Inovação } \\
\text { Seriedade }\end{array}$ & $\begin{array}{l}\text { Referência na qualidade } \\
\text { de ensino }\end{array}$ \\
\hline
\end{tabular}




\section{Notas de Ensino}

\subsection{Síntese das Notas de Ensino}

O caso FIP foi desenvolvido para ser utilizado em cursos de graduação ou pósgraduação, em disciplinas como Planejamento de Marketing, Comunicação Empresarial, Planejamento de Comunicação e Pesquisa de Marketing. O objetivo pedagógico consiste em oportunizar aos alunos a vivência de um processo de pesquisa, diagnóstico e planejamento de estratégias e ações relacionadas à imagem e comunicação de uma organização. Para tal, eles são estimulados a analisar os principais problemas levantados pelo diagnóstico, apontando alternativas que possibilitem a FIP a melhoria e consolidação da sua imagem, bem como o estabelecimento de uma comunicação mais eficiente com os seus diversos públicos.

Os dados primários para o desenvolvimento do caso foram obtidos por meio de entrevistas com a gerente de marketing da instituição realizadas nos meses de março a maio de 2012. Estes dados foram complementados com base em dados secundários, os quais foram obtidos por meio de consulta aos balanços sociais da instituição, ao diagnóstico da pesquisa de imagem realizada no ano de 2011 e de consultas ao Website da FIP.

Para melhor aproveitamento do caso como estratégia de ensino, sugere-se que sejam abordados previamente em aula conceitos sobre gestão da marca e comunicação empresarial. Da mesma forma, recomenda-se que o caso seja aplicado em dois momentos distintos. Primeiramente, deverá ser motivado um debate no grande grupo, o qual será feito posteriormente à leitura do caso e das bibliografias recomendadas, que são identificadas a seguir: Argenti (2006), capítulo 4 (página 79 à 104); Dias (2003), capítulo 11 (página 271 à 307); Ferrel e Hartline (2005), capítulo 10 (página 272 à 297); Kotler e Keller (2006), capítulo 9 (página 268 à 302), capítulo 10 (página 304 à 334), capítulo 17 (página 532 à 564); Ogden (2002), capítulo 1 (página 1 à 12), capítulo 2 (página 13 à 37); Shimp (2002), capítulos 1 e 2 (página 30 à 61). O professor poderá, ao aplicar o caso, selecionar as bibliografias que estejam relacionadas aos temas que serão estudados com a aplicação do caso. Em um segundo momento, será solicitado aos alunos que desenvolvam, em pequenos grupos, um plano de comunicação que, com base nas informações fornecidas no caso, aponte estratégias e ações de comunicação de curto, médio e longo prazo para a FIP. 


\subsection{Objetivos de Aprendizagem}

O caso FIP tem como objetivo geral oportunizar aos alunos a vivência de um processo de pesquisa, diagnóstico e planejamento de estratégias e ações relacionadas à imagem e comunicação em uma organização. Para tal, os alunos serão estimulados a analisar os principais problemas levantados pelo diagnóstico, apontando alternativas que possibilitem à FIP a melhoria e consolidação da sua imagem, bem como o estabelecimento de uma comunicação mais eficiente com os seus diversos públicos.

Além disso, os seguintes objetivos específicos podem ser abordados na aplicação do caso:

- Analisar a comunicação organizacional a partir de uma visão estratégica, considerando o conceito de comunicação integrada de marketing;

- Identificar as diversas ferramentas do mix de comunicação (propaganda, relações públicas, publicidade, promoções de vendas, venda pessoal, etc), bem como as características e utilização específica de cada uma delas.

- Analisar os conceitos de identidade, imagem e posicionamento, bem como a sua relação com a criação do brand equity.

\subsection{Aplicação do Caso de Ensino}

O caso FIP foi desenvolvido para ser utilizado em cursos de graduação ou pósgraduação, em disciplinas que abordem a imagem e comunicação empresarial, bem como o desenvolvimento de estratégias e ações de comunicação, como Planejamento de Marketing, Comunicação Empresarial e Planejamento de Comunicação, por exemplo. Além disso, pode ser aplicado em disciplinas que contemplem o processo de pesquisa, como Pesquisa de Marketing. Para melhor aproveitamento do caso como estratégia de ensino, sugere-se que sejam abordados previamente em aula conceitos sobre comunicação empresarial e gestão da marca.

Além das informações contidas no caso, é importante que os alunos sejam estimulados a buscar informações adicionais em outras fontes antes da realização do trabalho, especialmente relacionadas ao contexto no qual a instituição está inserida (ambiente geográfico, econômico, sócio-cultural, tecnológico e político-legal), ao perfil dos estudantes de graduação no Brasil, aos principais concorrentes da FIP (instituições de ensino superior no 
Paraná).

Recomenda-se que a aplicação do caso seja feita em dois momentos distintos. Primeiramente, deverá ser motivado um debate no grande grupo, o qual será feito posteriormente à leitura do caso e das bibliografias recomendadas e abordará as questões apresentadas na seção 6. Em seguida, deverá ser solicitado aos alunos que desenvolvam, em pequenos grupos, um plano de comunicação que, com base nas informações disponibilizadas no caso, aponte estratégias e ações de comunicação de curto, médio e longo prazo para a FIP. As duas etapas de aplicação serão detalhadas a seguir.

\section{Etapa 1 - Discussão Geral}

O debate em grande grupo deverá ser estimulado a partir das questões propostas na seção 6. A seguir, será feita a análise de cada uma destas questões, sugerindo-se teorias e bibliografias a serem utilizadas na implementação do caso de ensino.

\section{- Quais os problemas identificados em relação à imagem da FIP?}

Segundo Argenti (2006), a imagem de uma organização está relacionada à sua identidade. Esta é a manifestação visual da realidade da organização, conforme ela é expressa por meio do nome, logomarca, lema, produtos, serviços, instalações, folheteria, uniformes e todas as outras peças que são exibidas, criadas pela organização e comunicadas a uma grande variedade de públicos. A imagem, por sua vez, é o reflexo da identidade da organização. Ela corresponde à forma como a organização é percebida pelos seus diferentes públicos, sendo que, dependendo dos públicos envolvidos, uma organização pode ter diversas imagens.

Assim, os diferentes públicos formam percepções tomando como base as mensagens que as empresas enviam de forma tangível. Se a percepção que os públicos têm da organização refletir com precisão a realidade da organização, o programa de identidade terá atingido sucesso. Porém, se as percepções diferirem radicalmente da realidade, a estratégia de comunicação deve ser repensada (ARGENTI, 2006).

No caso da FIP, percebe-se uma grande variação em relação à imagem percebida pelos diversos públicos, o que demonstra a inexistência de uma identidade estabelecida, que contribua para a definição de uma imagem única e homogênea. A existência de lacunas entre a imagem percebida e a real, na percepção de diversos públicos, também revela a existência de problemas associados à imagem da instituição. Além disso, foram identificados alguns aspectos negativos, que depreciam a imagem da organização e que foram expressos em termos como "desorganizada", "interiorana" e "conservadora" pelos técnicos administrativos, “fragmentada", pelos professores e "fácil de entrar", pelos alunos. 
Com base no diagnóstico realizado, percebe-se a importância da organização repensar a sua identidade, a fim de minimizar os problemas identificados e construir uma imagem sólida e única. Nesse sentido, sugere-se que o professor estimule os alunos a discutirem os passos propostos por Argenti (2006, pp. 90-95), no subitem "Gerenciamento de Identidade em Ação", adaptando-os à situação específica identificada no caso da FIP.

\section{- Qual o posicionamento que a FIP deve estabelecer?}

Kotler e Keller (2006) afirmam que toda a estratégia de marketing é construída de acordo com o trinômio SMP - segmentação, mercado-alvo e posicionamento. A organização primeiramente deve descobrir as necessidades e grupos diferentes no mercado, estabelecer as necessidades e grupos que é capaz de atender de forma superior para, posteriormente, posicionar o seu produto e a sua imagem de modo que o mercado-alvo os diferencie da concorrência. Assim, se o trabalho de posicionamento da organização for adequado, será mais fácil definir o restante do planejamento e da diferenciação de marketing com base na estratégia de posicionamento. Por outro lado, se houver falhas na definição do posicionamento, o mercado poderá ficar confuso.

Os autores conceituam posicionamento como "a ação de projetar o produto e a imagem da empresa para ocupar um lugar diferenciado na mente do público-alvo" (KOTLER e KELLER, 2006, p.305). O posicionamento permite que a empresa estabeleça uma posição diferenciada na mente dos consumidores a fim de maximizar a sua vantagem potencial. Assim, um bom posicionamento de marca auxilia na orientação da estratégia de marketing, esclarecendo a essência da marca, quais os objetivos ela permite que o consumidor atinja e como faz isso de maneira única. O resultado do posicionamento é a criação de uma proposta de valor focada no cliente, ou seja, uma justificativa convincente para que o mercado-alvo compre determinado produto (KOTLER e KELLER, 2006).

$\mathrm{O}$ fato dos diversos públicos, como professores, técnicos administrativos e acadêmicos, terem percepções distintas acerca da imagem da FIP demonstra que há uma falha no posicionamento. Assim, além da construção de uma identidade forte, a instituição deve ainda estabelecer um posicionamento que alinhe os objetivos e valores dos públicos envolvidos, que esteja orientado especialmente para as necessidades e desejos do público-alvo (no caso, os alunos) e que permita a diferenciação da FIP em relação às demais instituições de ensino superior que concorrem no mesmo segmento. Para tal, sugere-se que os alunos sejam estimulados a debater as orientações propostas por Kotler e Keller (2006) para definição de um posicionamento para a FIP. 
- Como definir estratégias e ações de comunicação integradas, utilizando as diversas ferramentas (propaganda, relações públicas, publicidade, Internet, etc) a fim de estabelecer e consolidar a imagem da FIP?

A comunicação de marketing é o meio pelo qual as empresas buscam informar, persuadir e lembrar os consumidores, de forma direta e indireta, sobre os produtos e marcas que comercializam. Ela caracteriza a maneira pela qual a empresa estabelece um diálogo e constrói relacionamentos com os clientes, representando, dessa forma, a "voz" da marca (KOTLER e KELLER, 2006). A comunicação de marketing possibilita a transmissão e o compartilhamento de significado entre compradores e vendedores. Ela inicia-se com o consumidor e visa estabelecer um programa estratégico de comunicação persuasiva que considere cada contato entre ele e a empresa (FERREL e HARTLINE, 2005).

A comunicação integrada de marketing refere-se ao uso estratégico e coordenado dos diversos elementos promocionais, como propaganda, relações públicas, vendas pessoais e promoção de vendas, a fim de garantir o máximo de impacto persuasivo sobre os consumidores atuais e potenciais. A característica principal da comunicação integrada de marketing, dessa forma, está na coerência e uniformidade de mensagem em todos os elementos do composto de comunicação (FERREL e HARTLINE, 2005). Assim, os diversos fatores que compõem o composto de comunicação devem enviar uma mensagem homogênea aos consumidores, fortalecendo o posicionamento da organização e possibilitando a consolidação de uma imagem forte e duradoura.

No caso da FIP, a inexistência de uma imagem única e consolidada em relação aos diversos públicos denota problemas na comunicação. Assim, após a definição de um posicionamento para a instituição, o qual foi estabelecido na questão anterior, é importante que sejam eleitas estratégias e ações de comunicação que, de forma integrada, divulguem e fortaleçam este novo posicionamento. Para tal, é fundamental que o aluno tenha conhecimento dos diversos meios de comunicação (ou plataformas de comunicação, segundo Kotler e Keller, 2006), das características de cada um deles e das especificidades em relação ao uso à adequação das mensagens. Dessa forma, recomenda-se que estes tópicos sejam abordados ao longo da discussão, ou mesmo apresentados de forma expositiva pelo professor na primeira fase de aplicação do caso de ensino.

\section{- Como a FIP deve gerenciar o seu brand equity?}

O brand equity refere-se ao conjunto de ativos e passivos relacionados a uma marca, seu nome e seu símbolo, que se somam ou se subtraem do valor proporcionado por um 
produto ou serviço para uma empresa e/ou para os seus consumidores (AAKER, 1998). Esse valor pode se refletir no modo como os consumidores pensam, sentem e agem em relação à marca. Além disso, ele pode influenciar os preços, a participação de mercado e a lucratividade que a marca proporciona à empresa. Assim, o brand equity é um importante ativo intangível que representa valor psicológico e financeiro para a empresa (KOTLER e KELLER, 2006).

A gestão do brand equity está relacionada à criação e desenvolvimento de uma marca forte. Esta, por sua vez, pode ser definida como um nome, termo, sinal, símbolo ou design, ou uma combinação de tudo isso, destinado a identificar os produtos ou serviços de um fornecedor ou grupo de fornecedores para diferenciá-los de outros concorrentes. Assim, as marcas desempenham diversas funções: elas identificam a origem ou fabricante de um produto, permitindo que os consumidores - sejam eles indivíduos ou organizações - atribuam a responsabilidade pelo produto a determinado fabricante ou distribuidor; elas facilitam aos consumidores a análise e avaliação dos produtos, auxiliando e simplificando as suas tomadas de decisões de compras (KOTLER e KELLER, 2006).

Além disso, as marcas desempenham funções valiosas para as empresas, como a organização dos produtos em estoques e contabilmente, a proteção jurídica da empresa em relação a aspectos ou recursos exclusivos do produto (o nome da marca pode ser protegido por marcas registradas, os processos de manufatura podem ser protegidos por patentes e as embalagens e podem ser protegidas por direitos autorais, por exemplo), além da sinalização da qualidade do produto ou serviço para os consumidores. Assim, a gestão adequada da marca pode ser um meio da organização estabelecer uma posição diferenciada no mercado e gerar vantagem competitiva (KOTLER e KELLER, 2006).

Aaker (1998) classifica os ativos que fundamentam o brand equity de uma organização em cinco categorias: a lealdade à marca, o conhecimento do nome, a qualidade percebida em relação ao produto ou serviço, as associações feitas à marca em acréscimo à qualidade percebida e outros ativos do proprietário da marca, como patentes, trademarks, relações com os canais de distribuição, etc. O conjunto destes ativos pode acrescentar ou subtrair valor para os consumidores, auxiliando-os a interpretar, processar e acumular grandes quantidades de informações sobre produtos e marcas. Da mesma forma, ele pode afetar a confiança do consumidor na sua decisão de compra. Mais importante ainda é o fato de que tanto a qualidade percebida quanto as associações de marca podem aumentar a satisfação do consumidor com a experiência de utilização do produto ou serviço (AAKER, 1998).

Relacionado ao seu papel de adicionar valor para o consumidor, o brand equity tem o 
potencial de agregar valor para a empresa, gerando fluxo de caixa marginal por pelo menos seis formas: Em primeiro lugar, ele pode dar destaque a programas para atrair novos consumidores e reconquistar antigos. Assim, o fato da marca ser conhecida pode auxiliar na realização de promoções de vendas, por exemplo. Em segundo lugar, o desenvolvimento do brand equity pode estimular, por meio dos diversos ativos que o compõem, na lealdade à marca. A qualidade percebida, as associações e a familiaridade com o nome proporcionam razões para a compra e afetam a satisfação com o uso do produto ou serviço, o que pode estimular a segurança no consumidor e reduzir o incentivo para a experimentação de outras marcas. Assim, a lealdade não é apenas uma das dimensões do brand equity, mas também é influenciada pelo conjunto dos ativos que o compõe. Em terceiro lugar, o brand equity usualmente proporciona maiores margens, por permitir tanto um premium price quanto a melhor utilização de promoções. Em quarto lugar, o brand equity pode proporcionar uma plataforma para o crescimento via extensões de marca. Em quinto lugar, o brand equity pode dar um novo impulso ao canal de distribuição. Por fim, os ativos do brand equity auxiliam no estabelecimento de uma vantagem competitiva que frequentemente representa uma barreira real aos concorrentes (AAKER, 1998).

Assim, o desenvolvimento de uma marca forte e positiva, bem como a gestão adequada dos ativos relacionados à marca, no caso da FIP, podem afetar a experiência e a satisfação dos alunos no consumo dos serviços prestados, agregando valor aos serviços e à instituição. Além disso, é importante ressaltar para os alunos, na aplicação do caso, a relação que os diversos temas abordados, como a identidade, imagem, posicionamento, comunicação e brand equity, têm entre si. Kotler e Keller (2006) afirmam que, por meio do posicionamento da marca na memória e da criação de uma imagem de marca, a comunicação é uma importante ferramenta de formação do brand equity. Nesse sentido, recomenda-se que seja enfatizada para os alunos esta relação, bem como discutidos os principais elementos que poderiam auxiliar no gerenciamento do brand equity da FIP.

\section{Etapa 2 - Desenvolvimento do Plano de Comunicação}

A segunda etapa de aplicação do caso de ensino é recomendada para disciplinas que abordem o planejamento de comunicação. Nesse sentido, o caso FIP fornece um exemplo de situação organizacional que permite aos alunos refletirem sobre as estratégias e táticas de comunicação mais adequadas para a instituição. Para tal, sugere-se que a turma seja dividida em pequenos grupos, os quais deverão ser orientados em relação aos procedimentos para o desenvolvimento de um planejamento de comunicação. Como apoio bibliográfico, 
recomenda-se a utilização do modelo de planejamento de comunicação integrada de marketing de Ogden (2002). 


\section{Referências Bibliográficas}

AAKER, D. A. Marcas - Brand Equity: Gerenciando o Valor da Marca, $11^{a}$ edição. São Paulo: Elsevier, 1998.

ARGENTI, P. A. Comunicação Empresarial: A Construção da Identidade, Imagem e Reputação. Rio de Janeiro: Elsevier, 2006, capítulo 4 (página 79 à 104).

DIAS, S. R. (coordenador) Gestão de Marketing. São Paulo: Editora Saraiva, 2003, capítulo 11 (página 271 à 307).

FERREL, O. C.; HARTLINE, M. D. Estratégia de Marketing. São Paulo: Editora Pioneira Thomson Learning, 2005, capítulo 10 (página 272 à 297).

KOTLER, P.; KELlER, K. L. Administração de Marketing. São Paulo: Pearson, 2006, capítulo 9 (página 268 à 302), capítulo 10 (página 304 à 334), capítulo 17 (página 532 à 564).

OGDEN, J. R. Comunicação Integrada de Marketing: Modelo Prático para um Plano Criativo e Inovador. São Paulo: Prentice Hall, 2002, capítulo 1 (página 1 à 12), capítulo 2 (página 13 à 37).

SHIMP, T. A. Propaganda e Promoção: Aspectos Complementares da Comunicação Integrada de Marketing, $5^{\text {a }}$ edição. Porto Alegre: Bookman, 2002, capítulos 1 e 2 (página 30 à 61).

\footnotetext{
${ }^{\mathrm{O}} \mathrm{O}$ brand equity refere-se ao conjunto de ativos e passivos relacionados a uma marca, seu nome e seu símbolo, que se somam ou se subtraem do valor proporcionado por um produto ou serviço para uma empresa e/ou para os seus consumidores (AAKER, 1998).
} 